\title{
A EXPERIÊNCIA VIVIDA PELO SER-GESTOR NO DESENVOLVIMENTO REGIONAL EM UM CONSÓRCIO DE PEQUENOS MUNICÍPIOS
}

\author{
The living experience of the \\ manager being in the regional development \\ in a consortium of small towns
}

Envio 23.07.08 / Aceite 03.08.08

\author{
Luciana Flores Battistella ${ }^{1}$ \\ Rolf Hermann Erdmann ${ }^{2}$ \\ Milton Luiz Wittmann ${ }^{3}$
}

\begin{abstract}
Resumo
Este estudo tem como objetivo a compreensão da experiência vivida pelos gestores envolvidos no Consórcio de Desenvolvimento Sustentável da Quarta Colônia (Condesus/Quarta Colônia), a partir da reflexão de seus atores principais. O Condesus/Quarta Colônia é um consórcio de nove municípios que formam uma aliança estratégica em busca do desenvolvimento sustentável da região. Com base nas reflexões dos principais atores organizacionais, desvelase a experiência de ser-gestor do Condesus/Quarta Colônia. O desvelamento do fenômeno foi possível por meio de suas quatro essências significativas da experiência de ser-gestor do consórcio em questão. A primeira essência é a da superação, uma essência provocativa que

\footnotetext{
'Doutora em Engenharia de Produção/UFSC, Professora do Departamento de Ciências Administrativas da UFSM. Rua Floriano Peixoto, 1184, 5o andar - Centro - CEP: 97015-372 - Santa Maria - RS. Telefone: 0XX 5532209314. E-mail: luttibattistella@gmail.com

${ }^{2}$ Doutor em Engenharia de Produção/UFSC, Coordenador Curso de Pós-Graduação em Administração (CPGA)/ UFSC. Campus Universitário - Trindade - CEP: 88040-900 - Florianópolis - Santa Catarina - SC. Telefone: 0XX 48 3721 9365. E-mail: erdmann@newsite.com.br

${ }^{3}$ Doutor em Administração/USP, Professor do Departamento de Ciências Administrativas da UFSM. Rua Floriano Peixoto, 1184, 5o andar - Centro - CEP: 97015-372 - Santa Maria - RS. Telefone: OXX 5532209314. E-mail: wittmann@profwittman.com
} 
declara a superação das divergências, conflitos e rivalidades históricas, pessoais e políticas em nome de um futuro próspero em comum. A segunda essência desvelada foi a da força provocada pela união dos municípios por meio do consórcio. Vê-se que isso gerou um sentimento de orgulho (a terceira essência) entre seus membros e que esse sentimento ultrapassou as fronteiras físicas do consórcio, perpassando, hoje, por toda a comunidade, conforme as falas de seus gestores. A quarta essência do ser-gestor do consórcio compreende estar imerso em um processo, aceitando e lidando com as conjunturas, mudanças externas e internas e, diante disso, apreendendo a lidar com as frustrações e se auto-organizando continuamente.

Palavras-chave: Ser-gestor; Fenomenologia; Consórcio; Desenvolvimento Regional.

\begin{abstract}
This study aims to understand the living experience of the involved managers in the 'Condesus/ Fourth Colony', from the experience descriptions of its main actors. The 'Condesus/Fourth Colony' is a consortium of nine towns that join a strategic alliance searching for sustainable development of that region. From the main actors' reflections the experience of manager being in the 'Condesus/Fourth Colony' is unveiled. The unveiled phenomenon happens through its four significant essences of the experience of the manager being in such consortium. The first essence is overcoming, a provocative essence that states the overcome of differences, conflicts and historic, personal and political rivalries in the name of a prosperous future in common. A second essence is the strength. The strength is provoked by the union of towns through a consortium. It is noticed that it has generated a feeling of proud (the third essence) among its members and that, this feeling has gone over the physical borders of the consortium and, today, it is spread out in the whole society, according to its managers. The fourth essence of the manager being of the consortium means to be immersed in a process, accepting and dealing with the environment, external and internal changes and, facing this, learning how to deal with the frustrations and continuous self-organization.
\end{abstract}

Keywords: Manager Being; Phenomenology; Consortium; Regional Development.

\title{
1 Introdução
}

A região conhecida como a Quarta Colônia de Imigração Italiana no Rio Grande do Sul, situada próxima a Santa Maria, está localizada em sua maior parte na Serra Geral e nela encontra-se preservada área de Mata Atlântica. Em tal região é possível constatar um paradoxo: a falta de opções de lazer para os moradores de Santa Maria e a precariedade econômica e financeira da região da Quarta Colônia, com um potencial riquíssimo, sendo desperdiçado por falta de uma melhor sintonia entre os interesses do homem da cidade e o do campo.

Questionamentos acerca da construção e conduções de estratégias para minimizar a precariedade da região levaram este estudo ao encontro de uma organização denominada Consórcio de Desenvolvimento Sustentável da Quarta Colônia (Condesus/Quarta Colônia), formado por nove municípios da região central do Rio Grande do Sul. Este consórcio é administrado pelos prefeitos dos municípios envolvidos, com o apoio de uma Secretaria Executiva. A proposta de trabalho apresentada pelo Condesus/Quarta Colônia privilegia a valorização e o resgate da identidade regional, a busca por educação ambiental e patrimonial e o desenvolvimento sustentável.

Compreender o significado da experiência vivida pelos gestores do consórcio é a linha mestra que norteou este trabalho, procurando descrever seus processos gestacionais para responder aos novos contextos ambientais que marcadamente influenciaram a organização e

Rev. Adm. UFSM, Santa Maria, v. 1, n. 2, p. 263-274, mai./ago. 2008 
a sociedade ao longo dos tempos. É a partir das reflexões dos principais atores do Condesus que se descreve a experiência de gerir um consórcio. Diante do exposto, observa-se que este estudo encontra-se situado no paradigma interpretativo (MORGAN, 1980; MORGAN e SMIRCICH, 1980), em razão de seu caráter qualitativo, e utiliza-se do método fenomenológico hermenêutico (VAN MANEN, 1990; SEIDMAN, 1997), pois se baseia na experiência vivida da pessoa, procurando não analisar e interpretar, mas sim descrever a partir dos atores que vivenciaram o processo. Somente a pessoa que vivenciou uma experiência pode dar significado para ela, pois dela deriva seu entendimento e sua contextualização ímpar.

\section{Abordagem metodológica}

Este estudo segue uma inspiração fenomenológica, tendo como questão norteadora: Qual o significado da experiência vivida no Condesus/Quarta Colônia pelos seus gestores? Para buscar esclarecer esse problema, parte-se da seguinte pergunta de pesquisa: O que significa para você ser-gestor do Condesus/Quarta Colônia?

O foco do estudo centra-se nas vivências dos gestores, a fim de buscar compreender o significado de ser-gestor de tal organização. Estabelecidas a questão norteadora do estudo e a questão central de pesquisa, pretende-se atingir o objetivo central do trabalho: compreender o significado da experiência vivida pelos gestores envolvidos no Condesus/Quarta Colônia.

Este estudo posiciona-se no paradigma interpretativo, tendo como método de pesquisa a fenomenologia hermenêutica (VAN MANEN, 1990). Procura-se entender o fenômeno a partir do olhar de seus participantes, com suas falhas, erros e acertos, para que surja o aprendizado para a própria organização em estudo. Assim, dentro de uma metodologia qualitativointerpretativa (MORGAN, 1980; MORGAN e SMIRCICH, 1980), em que os atores principais desta pesquisa serão convidados a refletir sobre suas experiências ao longo do processo (VAN MANEN, 1990; SEIDMAN, 1997), deles partirão as reflexões sobre o significado da experiência vivida do Condesus para a busca do desenvolvimento regional.

Para atingir o objetivo proposto, realizaram-se entrevistas com os prefeitos que foram eleitos em suas localidades no mínimo duas vezes. Acredita-se que ao se entrevistar um prefeito que vivenciou a experiência do Condesus/Quarta Colônia por no mínimo oito anos (representando dois mandatos eletivos), o seu olhar sobre a problemática investigada ajudará a atingir o objetivo deste trabalho.

Diante do exposto, dos nove municípios que fazem parte do consórcio, sete prefeitos conseguiram se reeleger durante o período em análise (desde a criação do consórcio até os dias atuais) e, portanto, estavam aptos a serem entrevistados. Também foi entrevistado o secretário executivo de Condesus/Quarta Colônia, pois ele está presente em todo o processo de criação e desenvolvimento do consórcio. Desses gestores apenas um não foi entrevistado em função de sua indisponibilidade de horários e imprevistos.

Para a obtenção das descrições experienciais, foi utilizada a entrevista em profundidade, cujo objetivo é reconstruir a experiência vivida do entrevistado dentro do assunto estudado. As entrevistas partiram de uma questão aberta: $\mathbf{O}$ que significa para você ser-gestor do Condesus/ Quarta Colônia, proposta a cada entrevistado. Foram realizadas entrevistas que variaram de 60 a 90 minutos (SEIDMAN, 1997) com uma estrutura mínima (TAYLOR e BOGDAN, 1998). Para obter mais reflexões sobre o fenômeno, foram sendo acrescentadas outras perguntas derivadas da entrevista em curso (RICHARDSON,1999). Todas as entrevistas foram gravadas para posterior transcrição. A entrevista concentrou-se na questão norteadora de pesquisa proposta, solicitando 
reflexões detalhadas da experiência de participar do Condesus. O esforço do participante da entrevista em colocar suas experiências e sentimentos em linguagem é um processo de reflexão que permite reconstruir detalhes dos eventos que conferem significados para eles.

Após a obtenção das descrições experienciais, foi realizada a análise dessas descrições. A metodologia para a análise dos textos utilizada neste estudo é o procedimento de análise temática proposto por Van Manen (1990, p.78), podendo ser descrita nas seguintes etapas: obtenção das descrições experienciais (ou experiência vivida) por meio das entrevistas; transcrição das entrevistas pela entrevistadora; leitura das entrevistas (ou leitura do texto com as descrições experienciais), releituras, destaque dos temas e síntese criativa; e produção do texto fenomenológico. Para a análise temática, Van Manen (1990) recomenda o uso de três abordagens para descobrir ou isolar temas de um determinado texto: holística, seletiva e detalhada.

Ressalta-se a opção pelo recurso de substituição dos nomes dos gestores por virtudes (são elas: trabalho, disciplina, coragem, perseverança, articulação, responsabilidade e prudência).

\section{O significado da experiência vivida pelo ser-gestor do Condesus/Quarta Colônia}

Esta etapa começa com a apresentação da primeira essência: a da superação. Uma essência provocativa, que declara a superação das divergências, conflitos e rivalidades históricas, pessoais e políticas em nome de um futuro próspero em comum. Uma segunda essência desvelada foi a da força provocada pela união dos municípios por meio do consórcio. Vê-se que isso gerou um sentimento de orgulho (a terceira essência) entre seus membros e que esse sentimento ultrapassou as fronteiras físicas do consórcio, perpassando, hoje, por toda a comunidade, conforme as falas de seus gestores. Finaliza-se com a apresentação da quarta essência, como sendo um processo. Ser-gestor do consórcio significa estar imerso em um processo, aceitando e lidando com as conjunturas, mudanças externas e internas e, diante disso, apreendendo a lidar com as frustrações e se auto-organizando continuamente.

\subsection{Ser-gestor do Condesus é superação}

Todos os gestores do Condesus/Quarta Colônia preocuparam-se em descrever passagens que mostrassem como os nove municípios conseguiram ultrapassar as barreiras locais em nome de uma unidade regional: "Havia uma rivalidade extraordinária [...] era um bairrismo doentio [...] antes se procurava fazer para atrapalhar o outro (Articulação)".

A superação de conflitos, seja em função do bairrismo italiano, seja em função de divergências político-partidárias e até mesmo em função de diferenças pessoais, é o marco inicial do desvelamento das essências de ser-gestor do Condesus/Quarta Colônia. Era necessário superar tudo e conversar com o outro, que estava tão próximo e tão distante ao mesmo tempo. Os gestores relembram dos primórdios do consórcio e foram enfáticos ao retratar um movimento de desconfiança e medo geral, quando ainda prevaleciam orientações partidárias: "[...] quando nós formamos o consórcio [...] tinham-se restrições, se tinha medos [...] passou a fase do medo e fomos adiante (Trabalho)".

Num segundo momento nessa essência, foi observado que no dia-a-dia das questões gestacionais do consórcio, principalmente em termos de definição de obras, os gestores ainda apresentam divergências (embora em menor grau que do início do consórcio): "[...] rivalidade, um pouquinho até que é bom que exista [...] é uma coisa sadia [...] (Articulação)".

Rev. Adm. UFSM, Santa Maria, v. 1, n. 2, p. 263-274, mai./ago. 2008 
Como revela Articulação, ainda hoje, persiste por parte dos gestores certo receio de ter seu município prejudicado. Esse receio é mais patente quando o consórcio se depara com um prefeito recém-eleito, que nunca esteve em contato com o processo gestacional do consórcio. Esse novo-prefeito (neófito), que não entende e até mesmo questiona a dinâmica do consórcio, pois estava de fora de seu processo de gestão, é catequizado pelos gestores mais antigos. Nesses encontros, são destacadas as ações do consórcio para o desenvolvimento regional, no qual as perdas por eventuais cedências a outro município são menores que as conquistas obtidas no todo. As perdas eventuais, por cedência, em favor de um município vizinho devem ser explicadas à população que o elegeu. Com isso, ganha destaque o argumento de Follet e Child (apud GRAHAM,1997) sobre o conflito, sendo o mesmo inerente e não podendo ser de todo suprimido, pois conflito é diferença e deve ser capitalizado pela integração e não com base na dominação e na conciliação. (apud GRAHAM, 1997, p. 75), "o conflito, enquanto aparecimento e consolidação da diferença, pode ser um indício de saúde, uma profecia do progresso". A base para metodologia de soluções de conflitos por meio da integração passa pela necessidade de explicitar as diferenças, "colocar suas cartas na mesa, enfrentar a verdadeira questão, revelar o conflito, trazer a coisa toda à tona" (p.79), a integração não permite que o pensamento de alguém permaneça dentro dos limites de duas alternativas que são mutuamente excludentes. É necessário um comportamento circular $^{1}$ (no qual o nosso comportamento influencia o comportamento dos outros e o mesmo volta a nos atingir), enquanto base da integração que nos fornece a chave para o conflito construtivo.

Para que a superação ocorresse, foi necessário, em certo momento, no início do consórcio, um acontecimento marcante, que, por sua vez, levou os gestores a refletirem sobre o individualismo e a questão da integração regional. Esse acontecimento, aqui denominado de caso emblemático (citado por todos os gestores, espontaneamente), foi o marco da essência da superação. Com ele, os gestores começaram a vencer as diferenças, aceitar um pensamento mais regional, abandonar o seu bairrismo e orientações partidárias.

Tivemos uma luta muito grande [...] O governo ficou com os recursos [...] nos unimos os nove, compramos mais uma (retroescavadeira)[...] Para evitar que um município ficasse sem [...] (Coragem).

Fica claro que este ato de doar recursos entre nove municípios para benefício de um deles gerou um sentimento de congregação, um despertar para a ajuda mútua. Este caso emblemático fez suavizar as feições do outro e pensar que era possível um diálogo, um comprometimento maior da região com o desenvolvimento de todos. Agora estes gestores e seus municípios já não eram tão estranhos, já não estavam mais tão distantes e era possível e foi possível abrir um canal de conversação e compreensão mútua. A cooperação exigida nas relações interorganizacionais pressupõe a existência de confiança (BACHMANN, 1998; CHILD, 1999; LYLES, 2001; MARIZ, 2002), que pode ser analisada a partir de três dimensões: a confiança como cálculo; a confiança baseada na cognição e a confiança baseada em normas. É provável que as três dimensões da confiança atuem conjuntamente nos atores organizacionais. A confiança como cálculo é quando um ator calcula o risco de ser traído pelo outro, mas o fato de confiar torna-se mais vantajoso do que a possível perda diante de um comportamento oportunista da outra parte. Já a confiança baseada na cognição de modelos mentais compartilhados de interpretação da

1Para Follet (apud GRAHAM, 1997, p. 86), a compreensão do comportamento circular em situação de conflito possibilita "perceber que nunca consigo lutar com você, estou sempre lutando com você mais eu". 
realidade "é mais forte em ambientes sociais que dependem de características específicas de um forte arcabouço institucional. Sob essas condições, a produção de confiança é facilitada pelo conhecimento, normas e recursos de ação social" (MARIZ, 2002, p. 3). A confiança baseada em normas sociais é importante, mas não determinante na criação da confiança. O Condesus é um mecanismo que reduziu a incerteza e a complexidade ambiental para os nove municípios, possibilitando um canal de criação de confiança entre esses pares, mas, ao mesmo tempo que provoca confiança também apresenta riscos e custos, inerentes à criação de confiança.

Em várias passagens, os entrevistados demonstram que ainda hoje as situações de conflitos no consórcio têm de ser trabalhadas para atingir um amadurecimento e, assim, poder ir adiante nas realizações de ações concretas para a sociedade regional. Embora alguns gestores compreendam o consórcio como isento de conflitos, suas falas apontam para uma convivência pacífica regada por um determinado nível de conflitos, que são benéficos ao Condesus e que não prejudicam sua continuidade. Esses conflitos revelam a existência de uma preocupação com o que se está desenvolvendo no consórcio, pois a isenção total de conflitos significaria a falta de interesse no mesmo e o descaso com suas proposições.

Quando uma aliança estratégica (KLOTZLE, 2002) evolui para a formalização do acordo, ou seja, quando uma aliança alça a um patamar superior ao de um "acordo de cavalheiro" informal, ela passa a fornecer segurança institucional exigida para o seu desenvolvimento e alcança um grau de confiança cada vez maior entre os parceiros. Conforme realçado por Child (1999), a disposição para o pensamento no longo prazo relaciona-se com a duração ou não de tais alianças. O Condesus, com mais de dez anos oficializados e outros três anos de envolvimento para sua efetiva consolidação, venceu os primeiros cinco anos críticos, denominados de fase da implementação por Bleeke e Ernest (1995), Child (1999) e Mariz (2002), nos quais, conforme já observado, 50\% das alianças são interrompidas. Para Putnam (2002), a confiança promove a cooperação e a cooperação gera confiança, criando uma progressiva acumulação de capital social.

\subsection{Ser-gestor do Condesus é sentir-se forte}

Por meio das descrições experienciais dos gestores, foi possível compreender a essência da força em cinco movimentos complementares. Inicialmente, a força como poder econômico e poder advindo do conhecimento. Um terceiro ponto destacado é que a união proporcionada pelo consórcio levou os municípios da Quarta Colônia a ganharem força na hora da aprovação de seus projetos e seus gestores sentem-se abrigados e fortalecidos ao fazerem parte de algo maior, algo que lhes dê força e peso político. A essência da força é marcada pelo poder adquirido por tal consórcio em sua união. A força adquirida através do consórcio é tão importante que existe o receio de que o consórcio vire uma décima prefeitura tal sua força (quarto ponto abordado nessa essência). Embora os gestores não sintam isso como ameaça latente às prefeituras, mesmo assim, eles demonstram receio, pois existe um vício de fazer projetos através do consórcio para ganharem destaque, marcarem pontos mediante a união de forças dos municípios propiciada pelo consórcio (nove municípios, partidos diferentes em torno de um mesmo ideal: o desenvolvimento de uma região). Posteriormente, um quinto ponto é destacado na essência da força, que são os resultados obtidos pelo Condesus.

A força econômica aliada à força advinda do conhecimento (TOFFLER, 1980) fez com que essa essência fosse marcada no Condesus. Ciente dessas duas forças, os gestores observam como agem os órgãos governamentais e estaduais, ressentem-se de não ter chances sozinhos e vangloriam-se de que, com o consórcio, têm força para pedir e serem atendidos. Criam um 
movimento circular de ressentimento, de pesar por falta de força individual e um ufanar por ganho de força coletiva: "Quando se fala em consórcio, você fala em torno de trinta mil votos [...] um peso político que interfere [...]" (Coragem).

O poder que o Condesus foi adquirindo ao longo dos anos não chega a preocupar todos os gestores. Contudo, existe o receio de que o consórcio se transforme em uma entidade com maior poder que as prefeituras, visto que fazer projetos através dele tornou-se um vício. O receio do poder do consórcio está ligado ao vício de promover projetos integrados entre os nove municípios, pois os gestores estão cônscios da força adquirida do consórcio e embevecidos de orgulho por fazerem parte dele, pois declaram superados todos os tipos de rivalidades e querem apresentar os projetos sempre em conjunto, pois, assim, há mais força, portanto, maiores chances de obter recursos e maior visibilidade: "Nós criamos um vício [...] não sabemos mais buscar sozinhos" (Trabalho).

A união do consórcio transcendeu seus limites, suas fronteiras, pois os prefeitos da Quarta Colônia, ao fazerem partes de outras associações, levam a união do Condesus para as demais agremiações. Os gestores evidenciam a força do Condesus em termos de consórcio intermunicipal e sempre procuram ressaltar o consórcio por sua função de integração (efetivamente obtida) e por sua secretaria executiva ativa (como será destacado na essência do processo) é uma realidade distante dos demais consórcios que participam como prefeitos.

A essência da força permite compreender a visão dos gestores sobre como eles se percebiam quando gestores municipais, uma visão como um elo enfraquecido, de gestor destituído de poder (HARDY e CLEGG, 2001) e como se percebem agora, gestores de um consórcio que pensa sua região. Esses gestores, ao unirem-se em uma estrutura em rede, passaram a sentir-se detentores de uma poder maior, a compreender-se como fortes e a experienciar o impacto que essa força causa. De elos frágeis, de fios desconectados à integração por meio do consórcio, que os promovem a elos fortes, uma trama tal nó de marinheiro. A força é tanto que alguns gestores temem que o Condesus possa se sobrepor às prefeituras que o criou em função da dependência de recursos (PFEFFER e SALANCIK, 1978; PFEFFER, 1981; MINTZBERG, 1983; MORGAN, 1996), indo de encontro com a orientação gerencialista da voz funcionalista (HARDY e CLEGG, 2001) que discute o poder utilizado de maneira ilegítima por membros da organização. Portanto, como enfatizam Pettigrew (1987) e Morgan (1996), os gestores devem estar atentos ao contexto e controle desses recursos.

\subsection{Ser-gestor do Condesus é estar orgulhoso}

Ser-gestor do Condesus é estar orgulhoso dos feitos do consórcio, de tal maneira que esse orgulho transparece de dois modos complementares. Inicialmente, o orgulho aparece nas vozes dos gestores, pelo fato de o Condesus ter procurado, ao longo de seus projetos, resgatar e valorizar a cultura de sua comunidade. Isso foi, de certa maneira, uma provocação à comunidade e ela respondeu com o sentimento de orgulho por pertencer à Quarta Colônia. O orgulho da comunidade é fruto dos projetos do consórcio, que sempre buscam a educação e valorização de suas comunidades. Desde seu início, o Condesus ficou marcado pela busca de políticas públicas preocupadas com o resgate da dignidade de seus moradores.

[...] é um desencadeamento [...] muito complexo de atividades, de ações, de programas e [...] expiação dos demônios. Começa investigar esta história familiar, se começa oxigenar essas questões todas e a vê-la não como um peso ou uma roupa velha, mas como aquilo que estrutura a tua identidade, articula e dá sentido a tua própria existência e que a gente não pode se desfazer delas (Perseverança).

Rev. Adm. UFSM, Santa Maria, v. 1, n. 2, p. 263-274, mai./ago. 2008 
Trabalho reflete a questão do resgate cultural e, a realidade de hoje, em que os munícipes têm orgulho de falar que são da Quarta Colônia:

os munícipes não falavam em Quarta Colônia, quem falava era muito escondido, não tinha orgulho de ser da Quarta Colônia, então nós resgatamos este passado [...] buscamos a memória, mexemos com toda esta questão (Trabalho).

Num segundo momento dessa essência, compreende-se o fato de os gestores estarem orgulhosos do consórcio e, portanto, de si mesmos, visto que o Condesus deu maior visibilidade a suas ações e passou a ser visto com um modelo, um referencial pelos demais municípios:

Foi engraçado! Eu pedi para a Secretária de Turismo (Estado), um modelo de consórcio, um modelo de consórcio com pautas de rotas turísticas. Aí, mandaram o nosso estatuto! (risos) (Perseverança).

O resultado da união dos nove municípios na forma de um consórcio foi amplificação das vozes dos gestores, de suas forças e isso provocou o crescimento da visibilidade da região como um todo integrado. Observa-se que os gestores do consórcio não dissociam o seu orgulho do orgulho da comunidade, este recurso foi utilizado apenas com fins metodológicos:

\footnotetext{
Hoje [...] se você entrevista alguém, na imprensa [...] quando um prefeito [...] um vereador [...] ele fala: - nós da quarta colônia! O pessoal está esquecendo dos nomes dos municípios, muitas vezes [...] é a primeira coisa assim que transcende (Articulação).
}

O Condesus é algo que transcende a Quarta Colônia, pois outras comunidades gostariam de fazer parte. Outros municípios vizinhos também foram destacados como querendo fazer parte do Condesus/Quarta Colônia. Contudo, os gestores são unânimes em dizer que isso descaracterizaria o consórcio e esta identidade criada pelos nove municípios foi forjada em uma caminhada peculiar e a presença de municípios heterogêneos ao grupo poderia colocar em risco seus fatores de sucesso. Esta orientação vai de encontro ao apregoado por Leite, Gomide e Silva (2001, p.48), que evidenciam as dificuldades de implantar um consórcio em municípios heterogêneos quanto ao porte populacional e à realidade econômica e social, pois é provável a predominância do município de maior porte sobre os demais. Nesse sentido, o consórcio formado na Quarta Colônia opera em vantagem, pois é formado por nove municípios com histórias de imigração, emancipação e porte econômico e social que os integram.

O resgate do orgulho dos moradores da região só foi possível através do resgate de suas culturas, sejam elas italiana, alemã, portuguesa ou negra. Esse é o ponto de partida da essência do orgulho. Aos olhos dos gestores, as diversas comunidades que compõem o consórcio, ao verem suas culturas resgatadas e valorizadas, passaram a se aceitarem melhor (entre eles, entre eles e as demais comunidades da região e até mesmo fora delas) e de tal sorte que os prefeitos-gestores refletiram este orgulho para dentro da cultura corporativa do consórcio (SHETH, MITTAL e NEWMAN, 2001) bem como também permitiu o arrefecimento dos conflitos maiores.

O orgulho, tanto dos moradores como dos gestores, está ligado a elementos identitários profundos, conforme sugere Bergamini (1990). O resgate da cultura das comunidades que compõem o Condesus, a sua inserção em projetos de valorização da inculturação (processo 
de aprender a própria cultura) ou internalização, no qual a sociedade é convidada a refletir sua história e "expirar seus demônios", para usar as palavras de Perseverança, permite-lhes viver, hoje, na sociedade hibridizada de Cancline (1995), sem vergonha de sua imagem e de sua história. Destaca-se que o resgate e a valorização da cultura, para o Condesus, não estão tipificados como um resgate do passado para "vender memória", como foi criticado por Froehlich (2000), com o advento da multifuncionalidade do espaço rural. Froehlich lança ácidas críticas à transformação da população rural em atrações, como "fósseis vivos", símbolos de um período de rusticidade e bucolismo através de uma encenação maquinal, um rito circense, de uma realidade extinta.

O turismo, muitas vezes apontado como solução para a problemática do desenvolvimento regional sustentável, não é um caminho simples, mas uma longa caminhada de conscientização da população e até mesmo dos gestores, que devem entender e refletir que o processo para atingir sustentabilidade não está em projetos turísticos mostrando paisagens bonitas, mas vai além.

Quando os novos prefeitos são eleitos, os gestores devem desempenhar um papel adicional: o de ser-gestor do Condesus. Este novo papel (GOFFMAN, 2003) amplia seu centro de decisão, pois implica em ser-gestor regional. Tal papel torna-se um dos elementos fundadores da cultura corporativa do Condesus. Um exemplo disso pode ser observado no encontro promovido pelo consórcio entre os prefeitos recém-eleitos e os atuais prefeitos. Estes últimos fazem questão de participar para discutir a idéia do consórcio e seus projetos com os novos prefeitos. Este ritual de reunirem-se prefeitos e prefeitos ainda não empossados serve de apresentação de valores, normas e para a perpetuação do consórcio (SCHEIN, 2001; SHETH, MITTAL e NEWMAN, 2001). Um ritual no qual os prefeitos neófitos são catequizados no consórcio, tendo em vista a preocupação dos prefeitos atuais com a manutenção do consórcio face sua importância. Até mesmo aqueles prefeitos que não foram reeleitos participam e defendem a idéia do Condesus, pois acreditam em seus ideais, demonstrando que a cultura organizacional advém dos atores sociais que a compõem (SMIRCICH, 1983; MORGAN, 1996).

\subsection{Ser-gestor do Condesus é um processo}

A quarta essência para compreensão do ser-gestor do Condesus é que os gestores encontram-se imersos em um processo. Os gestores fazem parte de um todo maior em contínuo andar, lá para onde imperam as adaptações e o incrementalismo lógico (QUINN, 1980; IDENBURG, 1983). O entendimento que eles têm de ser-gestor do consórcio é de que não existe um fim, mas sempre uma busca. Busca por atender as necessidades da comunidade através da promoção de seus projetos institucionais. Então, ser-gestor é qualificar projetos, é esperar os recursos, é frustrar-se com a não vinda dos recursos, é não se deixar abater e qualificar outro projeto (às vezes replicando o anterior, que não fora atendido por falta de verbas), é ter uma secretaria qualificada e atualizar-se permanentemente, pois estão imersos em um processo de auto-organização permanentemente (WHEATLEY, 1999; MATURANA e VARELA, 2001).

O consórcio é um processo de transformação [...] então, todo o problema que se apresenta a gente vai atrás de soluções. E, então, eu vejo o problema como parte do cotidiano [...] O nosso plano de ação, tu não viu o de 2005 (risadas)? O de 2005 repete de novo o projeto [...] Eu gosto de repetir! (Perseverança).

Na busca por compreensão da quarta essência, ser-gestor do Condesus é estar imerso em um processo, foi possível compreender que estes gestores não partem de formalizações 
estratégicas previamente definidas. Não há um planejamento formal que possa servir de guia para os gestores balizarem suas decisões. Não existe um processo de formação de estratégias tal qual previsto nas escolas prescritivas de programação estratégica (Escola do Design, Escola de Planejamento e Escola de Posicionamento), segundo Mintzberg et al. (2000). Os gestores do Condesus apresentam em sua configuração estratégica traços das demais propostas descritivas de formação estratégica, no qual se ressaltam os modelos: Empreendedor, Aprendizagem, Poder, Cultural como predominantes nas suas vivências de gestores. Através da compreensão das falas dos gestores e das observações realizadas em campo foi possível entender que seus projetos estão adequados fortemente a um processo incremental e, eventualmente, segue uma orientação emergente (IDENBURG, 1993). Os projetos propostos nascem, como numa das falas de Disciplina, "como um fantástico, mas avançam para se tornarem um pequeno fantástico". Isso reflete o desejo de fazer algo com todos os requisitos, porém esbarra na liberação de recursos, e o que é realizado tem proporções mais reduzidas. Alguns pontos não resolvidos em determinados projetos são levados a outros projetos; nascendo; assim; um grande encadeamento de projetos, uma cadeia sucessiva de autogeração de projetos. Não há grandes discussões acerca dos projetos a serem realizados, pois boa parte deles é uma continuidade do anterior, uma tentativa de cobrir pontos que não foram contemplados ou o fato de uma idéia levar a outra, segundo a lógica incremental proposta por Idenburg (1993). Outro fator revelado como fator de sucesso para os projetos desenvolvidos no consórcio, nessa essência, é o papel do Secretário Executivo. Ter uma pessoa com o perfil de Perseverança, com dedicação integral aos problemas decorrentes do processo de gestão do consórcio, foi salientado pelos gestores como determinante para o estágio atual do Condesus, uma aliança estratégica como mais de dez anos de atuação (BACHMANN, 1998; CHILD, 1999; LYLES, 2001; MARIZ, 2002) e que segue se reinventando, como se percebe nas falas de Perseverança: "É um processo fascinante de aprendizado [...] cada ponta que tu abre é como se fosse um facho de luz que entra pelo prisma ou caleidoscópio".

\section{E no final, um recomeço...}

Este estudo teve como objetivo a compreensão do significado da experiência vivida pelos gestores envolvidos no Condesus/Quarta Colônia. Com este objetivo como guia, realizou-se a aproximação com a organização em pauta e seus gestores. Pode-se compreender o significado da experiência vivida pelos gestores do Condesus/Quarta Colônia por meio de quatro essências significativas: a superação, o sentir-se forte, o estar orgulhos e o ser um processo.

Este estudo, por estar calcado em um método fenomenológico de pesquisa, apresenta limitações inerentes à pesquisa qualitativa. Uma pesquisa fenomenológica não se propõe a comprovar relações de causa e efeito, pois se pauta por experiências pessoais. As pessoas, os contextos e os grupos não podem ser reduzidos a variáveis ou relação de causa e efeito. Assim, as essências compreendidas como significativas para o Condesus não devem ser buscadas nos demais consórcios, mas buscar a essência de ser-gestor de um consórcio. Tais essências, compreendidas neste trabalho, eventualmente, até poderão aparecer em outras experiências, mas não devem ser perseguidas como um modelo de ser de consórcio que deu certo. Recomenda-se a realização de futuras pesquisas feitas no sentindo de compreender a experiência de ser-gestor de consórcios, pois se evidencia uma carência de pesquisa fenomenológica em organizações em geral, inclusive considerando outros stakeholders não considerados neste estudo.

$\mathrm{Na}$ fenomenologia, busca-se acessar a experiência vivida, consciente de que as explicações nunca são idênticas à experiência em si. Ao desenhar as descrições pessoais das 
experiências vividas, sabe-se que as experiências próprias de uma pessoa são também possíveis experiências de outras pessoas e é neste sentido que as descrições fenomenológicas têm um caráter universal, intersubjetivo. A idéia principal da pesquisa fenomenológica é "pegar emprestadas" as experiências de outras pessoas - neste caso dos gestores do Condesus/Quarta Colônia - e as suas reflexões sobre a experiência de ser-gestor, com o objetivo de compreender o significado profundo de um aspecto da experiência humana no seu contexto total.

\section{Referências}

BACHMANN, R. Trust: conceptual aspects of a complex phenomenon. In: BACHMANN, R.; LANE, C. (Orgs.). Trust within and between organizations. Oxford: Oxford University Press, 1998.

BERGAMINI, C. W. Motivação no trabalho. São Paulo: Atlas, 1990.

CANCLINE, N. Consumidores e cidadãos. Rio de Janeiro: Ed. da UFRJ, 1995.

CHILD, J. Confiança e alianças estratégicas internacionais: o caso das joint ventures sino-estrangeiras. In: RODRIGUES, S. B. Competitividade, alianças estratégicas e gerência internacional. São Paulo: Atlas, 1999.

FROEHLICH, J.M. Turismo rural e agricultura familiar: explorando (criticamente) o cruzamento de abordagens e estratégias para o desenvolvimento local. In: ALMEIDA, J.; RIEDL, M. (Orgs.). Turismo rural: ecologia, lazer $\mathrm{e}$ desenvolvimento. Bauru: EDUSC, 2000.

GOFFMAN, E. A representação do eu na vida cotidiana. 11. ed. São Paulo: Vozes, 2003.

GRAHAM, P. (Org). Mary Parker Follett: profeta do gerenciamento. Rio de Janeiro: Qualitymark, 1997.

HARDY, C.; CLEGG, S. Alguns ousam chamá-lo de poder. In: CLEGG, S. et al. (Orgs). Handbook de estudos organizacionais: reflexões e novas direções. v. 2. São Paulo: Atlas, 2001.

IDENBURG, P. J. Four styles of strategy development. Long Range Planning, Great Britain, v.26, n.5, p.132-137, 1993.
KLOTZLE, M. C. Alianças estratégicas: conceito e teoria. Revista de Administração Contemporânea - RAC, Curitiba, v. 6, n.1, p. 85-104, jan./abr. 2002.

LEITE, C. C.; GOMIDE, C. de M.; SILVA,

I. G. Consórcios intermunicipais: modelo organizacional. In: Informativo CEPAM. Consórcio: uma forma de cooperação intermunicipal. São Paulo: Fundação Prefeito Faria Lima - Cepam. Unidade de Políticas Públicas - UPP, v. 1, n.2, p. 48-58, 2001.

LYLES, M. Aprendizagem organizacional e transferência de conhecimento em joint ventures internacionais. In: FLEURY, M.T.; OLIVEIRA JR.

(Orgs.). Gestão estratégica do conhecimento: integrando aprendizagem, conhecimento e competências. São Paulo: Atlas, 2001.

MARIZ, L. A. da C. Explorando os limites do conceito de confiança interorganizacional: o caso de redes de desenvolvimento tecnológico. In: ENCONTRO ANUAL DA ANPAD, 26., Salvador, 2002. Anais... Salvador: Anpad, 2002. CD-ROM.

MATURANA, H. R.; VARELA, F. J. A árvore

do conhecimento: as bases biológicas da compreensão humana. São Paulo: Athena, 2001.

MINTZBERG, H. Power in and around organizations. Englewood Cliffs: Prentice Hall, 1983.

MINTZBERG, H. et al. Safári de estratégia: um roteiro pela selva do planejamento estratégico. Porto Alegre: Bookman, 2000. 
MORGAN, G. Paradigms, metaphors and puzzle solving in organization theory. Administrative Science Quarterly, Ithaca, v.25, p.605-622, 1980.

MORGAN, G.; SMIRCICH, L. The case for qualitative research. Academy of Management Review, Mississippi State, v.5, n.4, p.491-500, 1980.

MORGAN, G. As imagens da organização. São Paulo: Atlas, 1996.

PETTIGREW, A. M. Context and action in the transformation of the firm. Journal of

Management Studies, v. 24, n. 6, p.649-670, 1987.

PFEFFER, J.; SALANCIK, G. R. The external control of organizacional. New York: Harper \& Row, 1978.

PFEFFER, J.Power in organizations.

Massachusetts: Ballinger Publishing Company, 1981.

PUTNAM, R. D. Comunidade e democracia: a experiência da Itália moderna. Rio de Janeiro: FGV, 2002.

QUINN, J. B. Managing strategic change. Sloan Management Review, Cambridge, Summer, p. 3-20, 1980.
RICHARDSON, R. J. Pesquisa social: métodos e técnicas. São Paulo: Atlas, 1999.

SCHEIN, E. H. Guia de sobrevivência da cultura corporativa. Rio de Janeiro: José Olympio, 2001.

SEIDMAN, I. Interviewing as qualitative research: a guide for researchers. New York: Teachers College Press, 1997.

SHETH; J. N.; MITTAL, B.; NEWMAN, B. I. Comportamento do cliente: indo além do comportamento do consumidor. São Paulo: Atlas, 2001.

SMIRCICH, L. Concepts of culture and organizational analysis. Administrative Science Quarterly, Ithaca, v.28, p.339-358, 1983.

TAYLOR, S. J.; BOGDAN, R. Introduction to qualitative research methods: a guidebook and resource. 3. ed. New York: John Wiley \& Sons, 1998.

TOFFLER, A. A terceira onda. 15 ed. Rio de Janeiro: Record, 1980.

VAN MANEN, M. Researching lived experience: human science for an action sensitive pedagogy. New York: State of New York Press, 1990.

WHEATLEY, M. J. Liderança e a nova ciência: aprendendo organização com um universo ordenado. São Paulo: Cultrix, 1999. 